\title{
Reflective Practice and Teacher Research: Catalysts for Teacher Growth
}

\author{
Goh Lay Huah \\ Department of Education, Faculty of Behavioral Science, Education and Languages, HELP University Malaysia, Malaysia
}

Received December 5, 2020; Revised January 11, 2021; Accepted March 12, 2021

\section{Cite This Paper in the following Citation Styles}

(a): [1] Goh Lay Huah, "Reflective Practice and Teacher Research: Catalysts for Teacher Growth," Universal Journal of Educational Research, Vol. 9, No. 6, pp. 1306-1315, 2021. DOI: 10.13189/ujer.2021.090620.

(b): Goh Lay Huah (2021). Reflective Practice and Teacher Research: Catalysts for Teacher Growth. Universal Journal of Educational Research, 9(6), 1306-1315. DOI: 10.13189/ujer.2021.090620.

Copyright $\mathrm{C} 2021$ by authors, all rights reserved. Authors agree that this article remains permanently open access under the terms of the Creative Commons Attribution License 4.0 International License

\begin{abstract}
In this article, I explained that concept and practice of teacher research were regarded as difficult for a novice teacher. I reflected how I could have benefited from the reflective practice and teacher research in promoting my growth as a teacher. This was a qualitative self-study research. It drew upon data from reflective journal notes as well as secondary sources of evidence derived from the findings of over 30 researches I had conducted. I reflected about teacher research at two levels - the personal perspective and the teachers' perspective. I shared how the reflective practice nurtured my research efforts. I observed how I grew as a teacher and how the notions of research changed as I delved more into the world of inquiry for continuous improvement of career as an educator. Research, specifically action research, became enquiry and learning in classroom practice. I also shared my thinking about what research meant for teachers in general, what issues they faced and what conditions hindered and enabled their research efforts. I noted that there were constraining factors and inhibiting factors that hindered the research efforts, but they were mitigated by conditions that motivated research. These were the opportunity conditions, the enabling conditions, and the enhancers. In conclusion, I noted that the strategies for continuous self-improvement were reflective practices and research into best classroom practices. In this way, reflection and research became ingrained in the practice; on-going educational research and development became a driver for change and continuous improvement, in addition to enhancing professionalism and quality learning.
\end{abstract}

Keywords Teacher Research, Reflective Practice, Teacher Development, Action Research

\section{Introduction}

It has long been recognized [1-4] that teacher research directs teacher professional identity and better quality teaching and learning. Research has indicated that engagement of teachers in research is desirable and has a beneficial effect on both teaching and learning, thus enhancing the quality of education. Richards [5] asserted that the benefits of teacher research contribute to the institutional success.

In the world of education, especially for academicians in higher education institutions, research has become one of the key performance indicators in their work life. It is undeniable that there is a strong correlation between research and the capacity for change. Staff who demonstrate that they are continuously involved in research are likely to be seen as highly motivated and engaged. They exhibit openness to learning. This also suggests they are flexible, adaptable and will bring a continuous improvement ethos to the workplace. Therefore, the practice of teacher research is an important agenda in professional development.

\section{Statement of the Problem}

Kincheloe [6] argued that through research, teachers "can explore the learning processes occurring in their classrooms and attempt to interpret them and begin to understand in deeper and richer ways what they know 
from experience". This benefit was widely acknowledged; however, when I was a novice teacher, the concept and practice of teacher research were regarded as difficult. As I reflected on my teaching career, I noted that,

I started my career in education as a teacher for 5 years before becoming a teacher educator for the next 25 years. As a novice teacher, I was prepared for my entry into the profession with basic teacher training and hardly any formal instruction in educational research methods. I remembered surviving from day to day, coping with lesson preparations. I had no thought for the need to engage in any systematic enquiry. But now on hindsight, I saw that as a novice teacher, I could have benefited from research for self-gain, to improve my practice and acquire self-knowledge, and to gain the self-confidence that I desperately needed. On reflection, I wondered - had I been armed with such knowledge and skills, would I have embarked on my career incorporating research into my practice and not till much later? (Ref-19-22, $11 / 5 / 2009)$

\section{Research Purpose}

In this research, I shared my thinking about teacher research at two levels - the personal perspective and the teachers' perspective. On the personal level, I shared how the reflective practice nurtured my research efforts. I observed how I grew as a teacher and how the notions of research changed as I delved deeper into the world of inquiry for continuous improvement. I also shared my thinking about research viewed from the perspective of teachers in general [7], what issues they faced and what conditions hindered and enabled their research efforts.

\section{Methodology}

This qualitative self-study research drew upon the data from my reflective journal notes that spanned over 20 years of my career as a teacher and educator. As a teacher, the reflective practice was a crucial element as I studied my actions as a teacher. Such reflection provided evidences about my learning through questioning and investigation to better understand what I knew and did. This reflective journal became written evidences of my inner voice as I contemplated before, during and after my teaching. They included observation notes of happenings in the classrooms, people behavior, and the learning environment, notes from readings and my personal response to learning points in relation to the research as well as jottings about discussions and brainstorming sessions with colleagues or students. The journal also recorded notes to myself during the personal moments when important ideas and insights dawn on me, as well as analysis of my actions and plans to follow-up and follow through.

The reflective notes were analyzed using the qualitative data content and pattern analysis technique. I organized the data into a form of explanation, understanding and interpretation of the people and situations I was investigating. I examined the data and highlighted important details that pertained to the research purpose. I then determined the category or code names and considered the significance of patterns that were elicited in relation to obtaining answers to this self-study. Quotes from my reflections were represented by the lines and date the text was taken.

A secondary source of evidence was derived from the findings of over 30 research I had conducted, published and unpublished, in as many years. In one of my research [8], I carried out a meta-analysis of these research and observed how my practice evolved into a personal philosophy which approached research as a catalyst for personal change and continuous professional development. Data derived from these secondary sources were cited accordingly.

\section{Literature Review}

\subsection{Teacher Research}

I used the term "teacher research" loosely to refer to research carried out by academicians and lecturers in their place of work, whether it be in a school classroom, a training venue, a lecture hall or lecture room in a higher education institution, or even in online instruction. I also used the term "teacher" as a general term to refer teachers, teacher educators, lecturers, trainers, facilitators or instructors, whose main aim was to bring effective learning to learners in whatever context or situation.

In this context, teacher research referred to all forms of practitioner enquiry that involves systematic, intentional, and self-critical inquiry about one's work [9]. It extended beyond thoughtful teaching of the kind often associated with reflective practice and should also involve making public one's findings. A significant amount of the teacher research might take place within the formal environments of study, for the purposes of program evaluation and addressing policy issues. But if teacher research was to become an integral part of teachers' professional practices, then it needed to extend beyond such settings and purposes [10] into the classroom that engaged in research.

\subsection{Reflection and the Reflective Practice}

The reflective practice was the ability to reflect on one's actions so as to engage in a process of continuous learning. It involved "paying critical attention to the practical values and theories which informed everyday actions, by 
examining practice reflectively and reflexively. The notions of reflection-in-action, and reflection-on-action were central to Donald Schon's [11] efforts, and constituted valuable insights to me. A thought contained the possibility of the situation of which it was the thought. What was thinkable was possible too [12]. The practices of reflection in research, especially action research were varying formats of inquiry to better understand the social and education problems and to seek to improve the quality of life [13].

Learning is a process, not a product, and so is teaching. Educators should take time to reflect on their teaching practice and assess their students' learning in order to continue evolving and improving their students' learning experiences [14].

'Reflection', and variations of the term - 'reflective teaching,' 'inquiry-oriented teacher education', 'teacher as researcher' and 'reflective practitioner'- were linked with discussions of practice and the professional growth of educators. Dewey [15] distinguished between action based on reflection and action that is impulsive or blind, and he emphasized on the need to develop certain attitudes of open-mindedness and skills of thinking and reasoning in order to reflect teaching [16]. This has influenced the way many researchers and teacher educators have thought about reflective teaching. As "reflective practitioners" [17], the teacher achieved greater ownership of the practice by becoming systematically self-evaluative.

Reflection-on-action was also referred to as reflective practice. This was the reflecting done after the event: thinking through, and often discussing the incident with a colleague or supervisor. To an extent we all have done it whether formally at work, or informally over coffee / beer either with colleagues or friends / family. Teachers who reflected on their practice, feeling and reasons behind their action were more deliberate and purposeful in their teaching and tended to have a more thoughtful climate in their classroom.

Reflection brought about active self-development. It allowed us to think more deeply, think things through, question policy and practice more fully, examine professional practice, engage critically with current issues rather than accept that what is written by the expert mush be right. Reflection allowed the researcher to be a lifelong learner [18,19].

Our reflection, and its value to us, could be hugely enhanced by a greater understanding of the process. It would enable us to generate our own vital questions formulate and respond to our own learning needs. The teacher might be a skilled practitioner. But much of the knowledge and expertise was embedded in the practice. There was an advantage in making some of these implicit understandings and skills explicit - both in order to explain and clarify them so the teacher could develop them more effectively, and also in order to pass them on to colleagues. Reflection had another function: thinking about and sorting out difficulties, problems, and errors and thinking out the solution rationally and systematically. Reflection and self-evaluation are extensions of cultivating research as part of the teacher's professional practice. Self-evaluation and analysis should be ongoing in the quest for the best classroom practices.

\section{Findings and Discussion}

\subsection{Thinking about Teaching: Reflecting on My Practice}

I shared my personal perspective as a teacher and educator and my involvement in research. Right after graduating from University, I taught in schools for 5 years and subsequently in teacher training for 25 years. In thinking about my teacher, I identified my career along the phases of teacher progress [20]: early idealism, survival, recognizing difficulties, reaching a plateau and moving on. In one of my research [21], it was noted that "most beginning teachers often started out in the early idealism stage full of enthusiasm and zealousness to teach their pupils". But this often turned into panic and a sense of helplessness when they were faced with unforeseen or unexpected problems very dissimilar to their expectations and preferences. They swiftly entered into the stage of survival. Many in this stage experienced reality shock when they discovered that life as a teacher was so far removed from their previous conceptions and expectations. The demands of teaching in their first year were significantly greater than what they had conceived or expected. Next came the awareness of the difficulties and their causes, their limitations and concerns about performance. Then came the phase where the teacher was beginning to cope with the teaching situation and achieving some success, anxious to establish routines which work and a growing resistance to trying new things. This was a crucial stage. Without support, the teacher might 'plateau out' and 'slide', or, burn out. With support, the teacher might move on towards greater professional development.

\subsubsection{Early Idealism and Survival}

As a new teacher in school armed with basic teacher training and little research skills, I was always thinking of ways to teach effectively and was only one day ahead in my lesson preparations. Within this early idealism and survival phase, I could not perceive myself as a good teacher researcher material. In my early years as a teacher, research was a concept still beyond my understanding, skills and capability. "It was inconceivable that a regular teacher like me could embark on any form of research. I lacked the confidence to venture into it" (Ref-3,03/03/2006). It appeared difficult to learn [22]. I was in awe of anybody who could carry out research. I 
know now that this is a sentiment shared by many [23]. In Malaysia, the benefits of research were recognized, but many teachers were wary and apprehensive about carrying it out.

\subsubsection{Recognizing and Acknowledging Difficulties}

Looking back, I realized that even though "I might not have been a "natural born teacher", I "grew into a teacher" (Ref-6, 11/03/2009). It started with recognizing and acknowledging difficulties and devising ways to handle issues. In this way, I acquired and learned new knowledge, skills and experiences from my students in the classrooms. I also gained satisfaction in sharing with my fellow colleagues. We shared the common goals of ensuring that student learning was carried out effectively. Within this phase of my teacher development where I recognized and acknowledged the difficulties I encountered, the seed of reflective practice was planted. I embarked on the unceasing practice of examining my abilities as a teacher, and seeking ways to improve so that my learners can benefit from my teaching. I was able to make sense of, and respond to a given problematic situation in the classroom because the store of my schemata enabled me to automatize routines. As a teacher right in the midst of events and problems happening, I felt that I was able to study the situation and find solutions for it [24]. But even as I became more competent, I had not made the connection between the practice of teaching and the need to engage in any systematic or research enquiry. Reflection remained thoughts about teaching and improving my skills and techniques to benefit my learners. Such thoughts were fleeting, undocumented, unsystematic and clumsy. I saw myself reflected in Schon's [25] description,

"competent practitioners usually know more than they can say. They exhibit a kind of knowing in practice, most of which is tacit...Indeed practitioners themselves often reveal a capacity for reflection on their intuitive knowing in the midst of action and sometimes use this capacity to cope with the unique, uncertain, and conflicted situations of practice."

\subsubsection{Reaching the Plateau and Moving On}

It gradually dawned on me that generating new knowledge from inquiry and research was not the sole prerogative of universities and research and development experts [26]. My earlier research exposure was the traditional quantitative designs. As my teacher career developed and I gained more knowledge and experience, I started to realize that research was not always a major project initiated from the top. I drifted towards more qualitative methodologies when I saw its applicability in enhancing the understanding of my learners and improving my teaching strategies [27]. Carrying out inquiries into minor but relevant educational issues was equally important. And so my attitude towards research underwent a gradual shift towards interpretivist research merging classroom research with the practice of teaching, studying my students and ways to improve their learning as I carried out my instruction. I thus developed the reflective practice in my later research endeavors.

Certain teachers reached the plateau in their teacher development and are content to remain in their comfort zone till the end of their teaching career [28]. I believe that as I engaged in thoughtful reflection about my practice and assessed my students' behavior, I continued to evolve in my personal learning experiences. In this way, I moved from the plateau phase in teacher development towards being an experienced teacher. Internalizing the reflective practice and integrating action research into my teaching allowed me to move on towards continuous personal and professional growth. "As an experienced teacher, I was able to make sense of, and respond to a given problematic situation in the classroom because the store of my schemata enabled me to automatize routines" (Ref-7-8, 21/07/2006). As a teacher right in the midst of events and problems happening, I felt that I was able to study the situation and find solutions for it [29]. As a teacher, I was the direct participant in the classroom social event and am capable of influencing the psychological development of the individual integrating the learning experiences of the pupils to the collective and communal needs of society and so contribute to matters of educational equity and social justice in the research community, in particular, the action research community today [30].

\subsubsection{Becoming a Reflective Practitioner}

"What is this life, if full of care, we have no time to stand and stare?" [31]. In my research experiences I did a lot of 'staring' - reflecting, looking inwards into myself as a teacher researcher and a teacher educator. "Reflective practice became a systematic way of studying my own experiences to improve the way I work". (Ref-10, 08/04/2003). I kept a reflective journal detailing my experience, observations and thoughts during sessions with my students. I revisited my past teaching through such notes and jottings. Re-reading them gave me new insights that triggered ideas for upcoming lesson. And when I started to routinize the practice, I observed that most of my reflective practices were action-research oriented.

\subsubsection{My First Action Research Attempt}

First time experiences that were momentous were usually epiphanic and life-changing, like my first foray into action research [32]. It was to explore my role as a facilitator while collaborating with adult learners in one of the courses I taught. I was acquainted with the concept of the teacher playing the role as facilitator when my lecturers mentioned it 20 years ago. However, through my career as a teacher and an educator, it remained a word, a 
term, a vague inclination to try it out one fine day. When the opportunity arose, I conducted an action research of myself as a subject of study, the facilitator, collaborating with three English Language teachers who were to produce a learning package of their choice. For a period of three months, I kept reflection notes made by me and my three co-researchers. From this experience, I observed the emergence of three phases in my development as a facilitator: control, letting go, and finally, collaboration. In the beginning, I was in control, providing input, setting the pace, and directing the interaction among my learners. This was teacher directed instruction and they found that helpful. As learning progressed, the learners had their work momentum started and going and they started to experience independent learning. I was no longer the central figure in their learning and no longer controlled the learners' work pace and direction. My facilitator's role as an authority and source of knowledge was reduced. I had to adjust to letting the power and control go into my learners' hands. I learned that the teacher must be willing to surrender power and authority in the learning process and become co-learners with other participants. Only then could I progress into the third phase and truly assume the facilitator role. "I realized that the issue of who had control and power in the learning process no longer existed during this last phase. It was replaced by collaboration between facilitator and learner - a mutual sharing of thoughts, a one-on-one communication. Knowledge was created together, and not transferred from teacher to learner". (Ref-11-13, 22/06/2000)

This first action research attempt opened for me boundless possibilities to try out strategies and techniques. I went on to explore my teaching with other action research [33-41]. The positivist research had previously allowed me to acquire the wider view of situations. Action research allowed me to delve into myself for answers. I was the participant as well as the observer, with my learners as participants in my research. "Such academic exercises have enriched me. I learned in action, as I learned when I reflected on my actions; and finally I 'learned' my learners as they 'learned' me". (Ref-7, $22 / 06 / 2000$ ) Additionally, through the voices of my significant others -my learners - I invariably reached a better understanding of my capacity as a teacher. Having gained experience and skills as a researcher, I developed the confidence to think about teacher research and how I might share this passion with others.

\subsection{Thinking about Teacher Research}

Thinking about teacher research from the perspective of a teacher, I realized that routinizing the reflective habit and teacher research was a journey that required more than the right attitude. These practices required a whole support structure. Over the years, I had conducted a number of research courses to teachers in schools and institutions, and I observed that their reaction to the idea of having to do research was often that of caution and anxiety [42]. I had often wondered why that was so, what the teachers' attitudes were, what motivated them, and what conditions hindered their research efforts, and what sort of conditions were needed to support and sustain it. However, evidence on such issues of teacher research had not been plentiful [43]. Borg [44] noted that teacher research was clearly not a widespread activity. Many teachers lacked the culture of collaborative professional learning by which they might work smarter ([45]. Even in schools where the culture of teacher research had been initiated, putting in place conditions for sustainable research practice were difficult [46]. Consequently, I studied [47] the conditions that hinder and conditions that support teacher research and read around the subject as well as reflected on my learning experiences. I concluded that there were constraining factors and inhibiting factors that hinder the research efforts, but they were mitigated by conditions that motivated research. I labelled these as the opportunity conditions, the enabling conditions, and the enhancers.

\section{Factors that Hindered Teacher Research}

Constraining factors and inhibiting factors hindered teacher research. These factors could explain teachers' reluctance in carrying out research.

Constraining factors were the key factors that thwart the research initiatives. Concerns about barriers to teacher research had been continuously debated in the past [48]. Not surprisingly, time and workload were major constraints for teacher-researchers who were considering starting a research. As Richards [49] stated, 'the time required to do even the most limited research project is immense'. Very often, teachers were busy and overwhelmed with just the day to day demands of their jobs. Sharp [50] reported that teachers found the major challenge lay in finding time to focus on research and suggested that time for collaborative research be included in the teachers' time-table. Nair [51] suggested that completed research may be rewarded with time given to conduct more research or take a further qualification.

Inhibiting factors were deterrents to the research practice. The teachers' lack of knowledge and skills, and the lack of expert guidance and mentoring inhibited their desire to carry out research [52]. Teachers were the best people to carry out classroom research because of their rich schemata; they were also right in the midst of events and problems happening and were often able to make sense of, and respond to a given problematic situation in the classroom. However, research was still largely being regarded as a very difficult enterprise, a time-consuming task which could only be achieved by those who had 
already possessed the knowledge to do so [53]. These difficulties were familiar to me in my early years as a teacher and therefore I understood very well the teachers' sentiments.

Individual attitude towards research was the most important factor for teacher research. Unfortunately, many teachers felt that research was a formidable endeavor [54]. This could have explained their reluctance to be involved in research and the resultant lack of research done. Teachers also talked about how busy and overwhelmed they were in just dealing with day to day demands of their jobs. The notion that teachers required time to analyze what they were doing and consider the educational worth of their practices was often at odds with the priorities in institutions, which typically attached a much higher value to immediate, unreflective action [55]. In addition, they were largely intimidated by the conceptual and technical skills they may need to learn [56], and so failed to make the link between their daily practice and the academic research process.

The perceived lack of the utility value of research and the perceived lack of recognition for the research efforts were manifested in the teachers' expression of disinterest towards research. Nair [57] explained that there was not more evidence of teacher research impacting on practice due to the social and political contexts in school; the school cultures; and teachers' perceptions of their roles and personal efficacy. The link between teachers' daily practice and the academic research process is not often made. So, teachers may undervalue their currently practiced skills. The lack of recognition and a culture which did not prioritize professional knowledge development were also deterrents to teacher research. Teachers felt that their institutions did not value their research [58].

Similarly, Cochran-Smith \& Lytle [59] expressed some concern about teachers having a basic contempt for research that prevented them from engaging with it. Nair [60] believed that the lack of power to alter systems may have contributed to some teachers' reluctance to be involved in research. Such barriers could have affected a teacher's efficacy as a researcher.

For a culture of systematic evidence-based teacher practice to exist sustainably, the creation of a conducive climate and support structure was a necessary pre-requisite. There was a real need to provide the conditions to develop innovative practice through research enquiry whereby teachers were able to solve problems by achieving deeper understanding [61].

\section{Motivating Teacher Research}

Having integrated the reflective practice and research in my practice, I believe the effort to be worthwhile because "investigating a question of (my) own choosing was motivating and reflecting on (my) own practice reinforced the importance of the teacher's role," [62]. The preceding discussion had identified many stumbling blocks along the research journey. These hindrances could be alleviated by the creation of more favorable conditions for teacher research. More teachers would have the courage to embark on a journey of learning with their students, if they knew they would be helped. The conditions that supported and encouraged the research efforts could be categorized as: the opportunity conditions, the enabling conditions, and the enhancers.

Opportunity conditions were achieved by overcoming the key constraints of time and work load. In Maslow's Theory [63], the deficiency needs had to be met according to the hierarchy of needs. Similarly, to motivate research, opportunity conditions had to be met. Due consideration should be given to alleviating the teachers' key constraints by reducing work load and increasing time given to research. This would allow them the opportunity to think about moving upwards to their next level of professional advancement by doing research. Once the opportunity conditions were met, seeking to satisfy professional growth might spark the inclination towards research as inquiry in improving teacher practices.

Teachers could also be persuaded to view themselves as both producers and consumers of research experiences rather than just the former. Research and the reflective practice added to the store of knowledge and brought about professional development that ultimately benefitted our learners, and "not merely for the uncritical glorification of knowledge generated through practitioner research" [64]. This involved a recognition that practitioners were professionals who must play active roles in formulating the purposes and ends of their work as well as the means. As Stenhouse [65] stated, " $a$ research tradition which is accessible to teachers and which feeds teaching must be created if education is to be significantly improved". Teachers as research practitioners had theories too that could contribute to the knowledge that informed the work of practitioner communities. Teachers needed to realize that the generation of knowledge about good practice and good institutions were not the exclusive property of universities and research and development centres. Research and inquiry could be seen as a ground up process, with classroom teachers generating the knowledge and experience most pertinent and relevant to our conditions [66].

In addition, the provision of various platforms and opportunities to disseminate findings and allow the voices of teacher researchers to be seen and heard was a significant condition for teacher research. Publishing research on institution websites motivate teacher researchers, and "lead to the recognition that teacher research is directly related to improving pupils' lives and so has a moral dimension" [67]. Teachers should also be encouraged to publish in academic journals and share their 
findings in seminars and conferences in order to reach a wider intended audience. Kitchen and Jeurissen [68] reported that "being able to share their stories, journeys, and findings with others was extremely rewarding, empowering, and motivating".....and on the other hand ... "not having access to a wider audience of some kind was constraining and frustrating.." (p. 39). These platforms of sharing and dissemination would also aid in dispelling the misperceptions about research as the field of 'experts' only and therefore aid in improving the perceived utilitarian value of research.

Enabling conditions were important to drive research. These were conditions such as imparting knowledge and skills, providing training and guidance as well as support and collaboration to teacher researchers. These were necessary tools that would enable the teachers to carry out the research activity. In order to provide the support for a community of enquiry to be built between research and practice among novice researchers, mentors who played the role as 'translators, envoys and mediators' of the research practice were needed to guide through the whole process. The National Foundation for Educational Research project in the United Kingdom [69] that utilized a small team of professional researchers working collaboratively with teachers in 15 primary and secondary schools to engage in research "gave teachers a sense of professionalism and put them in the driving seat". Kitchen and Jeurissen [70] reported that teachers talked about feelings of loneliness while carrying out their research and suggested that collaborative actions in research "helped the teachers to manage the research process and persevere when problems seemed insurmountable" (p. 38). Therefore institutions that aspired towards a research climate should possess a positive attitude towards research and involve senior management and others in study. They should also have systems in place for regular feedback from staff who had undertaken professional development.

Enhancers were important in providing the incentives and building the right attitude for sustained research efforts. They came in the form of recognition and the provision of various platforms for sharing and dissemination of research ideas that motivated teachers to continue with the research efforts and enhanced not only their research skills and knowledge, but also enhanced the quality of their classroom practices as well. In turn, these researchers may become mentors and motivators to other researchers. Such positive attitude towards research was important in building a research-engaged school. On a similar note, Nair [71] suggested the provision of incentives to promote teacher research in the form of monetary allowance, common free time to use for collaborative research and publications as well as conference presentations as variations of recognition. The dedication of the teachers and the support of institution leaders are also key conditions in promoting a learning culture.

\section{Concluding Thoughts}

It was a fact that not all new teachers who entered the teaching profession passed with distinction; teachers with 'pass' and 'credits' were also admitted. The latter most probably started out as mediocre teachers. I was one such mediocre teacher. Nevertheless, with the right motivation, attitude and commitment towards continuous self-improvement, a teacher like me who passed out from training with mediocre results could grow beyond mediocrity to become an excellent teacher. Among the strategies for continuous self-improvement were reflective practices and research in the quest for the best classroom practices.

"The working life of an educator is stimulating, full of dilemmas, incompleteness, uncertainties and satisfactions. But so much of it goes unremarked, undocumented and become lessons lost because it was deemed not worthwhile recording" [72]. To prevent the loss of such rich and valuable sources of data, I had adopted the workplace- the school, the university - and my students, and the staff and all my experiences as the 'university of life' [73] within which as a teacher practitioner I could utilize to conduct research, to reflect, to act, and to learn and to share. Such thinking while teaching made me more critical of my professional self, more mindful of my shortcomings and motivated me to change for professional improvement.

In conclusion, thinking in teaching generated research that was relevant and realistic and encouraged reflective practice. As a teacher who cared about developing to its fullest potential the talent and creativity latent in each individual student, I realized the need to continually broaden my horizons, to change and to improve my practice. Thinking about teacher research made me empathetic about the plight of other teachers who would be researchers. A support structure of opportunity conditions, enabling conditions and enhancing conditions must be in place to scaffold and motivate such efforts. Reflection and research then become ingrained in the practice; and I saw clearly that it was on-going educational research and development that drove change and continuous improvement, and enhanced professionalism and quality learning.

\section{REFERENCES}

[1] Ubaque, Diego Fernando, Castañeda-Peña, Harold. (2017). Teacher Research: Uncovering Professional Identities and Trajectories of Teacher Researchers through Narrative Research. A Colombian Case International Education Studies; Vol. 10, No. 3; Canadian Center of Science and Education, 2017, https://files.eric.ed.gov/fulltext/EJ113853 0.pdf, ISSN 1913-9020 E-ISSN 1913-9039.

[2] Lankshear, C. \, M. Knobel, A handbook for teacher research: From design to implementation. Maidenhead, Open 
University Press. 2004.

[3] Lewin, K, Action Research and Minority Problems, Journal of Social Issues, 2(4), 34-46, 1946.

[4] Stenhouse, L, An introduction to curriculum research and development, London, Heinemann, 1975.

[5] Richards, Keith, Qualitative Inquiry in TESOL, New York, Palgrave Macmillan, 2003.

[6] Kincheloe, J, Teachers as researchers: Qualitative inquiry as a path to empowerment, 2nd ed, New York, Falmer, 2003.

[7] Goh Lay Huah, The Conditions For Teacher Research In Schools, Paper Presentation 2009, Second Malaysia-Thailand Joint Educational Research Conference 2009, Hotel Pullman Bangkok, Thailand, 14 - 18 November 2009.

[8] Goh, Lay Huah, '4r 2s' Approach To Research: A Personal Philosophy For Change And Teacher Professional Development. Asian Education Action Research Journal (AEARJ), Vol. 1, 2012, ISSN 2289-3180.

[9] Cochran-Smith, M, S.L. Lytle, Inquiry as Stance: Practitioner Research for the Next Generation, New York, Teacher's College Press, 2009.

[10] Borg, Simon, Conditions for Teacher Research. English Teaching FORUM - 2006 - Volume 44, Number 4: Bureau of Educational and Cultural Affairs Office Of English Language Programs, 2006, http://forum.state.gov/vols/vol4 4/no4/p22.htm.

[11] Schon, Donald, Educating the Reflective Practitioner, Presentation at the 1987 Meeting of the American Educational Research Association, Washington, DC, 1987, http://hci.stanford.edu/other/schon87.htm.

[12] Wittgenstein, Ludwig, Tractatus Logico-Philosophicus, London, Routledge \&Kegan Paul Ltd, 1921, https://philpapers.org/rec/WITTLG.

[13] Zeichner, K M, A critical analysis of reflection as a goal for teacher education, Educ. Soc. vol.29 no.103 Campinas May/Aug. 2008, http://dx.doi.org/10.1590/S0101-73302008 000200012, ISSN 1678-4626 2008.

[14] Smith, Nina, Reflective Practice in Higher Education Instruction, https://evolllution.com/opinions/reflective-practice-in-highe r-education-instruction.

[15] Dewey, J, How We Think. 1st ed. Boston, D.C, Heath \& Co, 1933.

[16] Calderhead, James and Gates, Peter, Conceptualising Reflection In Teacher Development, UK, Taylor \& Francis, 2004.

[17] Schon, Donald A, The reflective practitioner: how professionals think in action, New York, Basic Books, 1983.

[18] Goh, Lay Huah, ‘4r 2s' Approach To Research: A Personal Philosophy For Change And Teacher Professional Development. Asian Education Action Research Journal (AEARJ), Vol. 1, 2012, ISSN 2289-3180.

[19] Goh, L.H, Loh, K.C, Let Them Fish, Educational Action
Research Journal, Vol. 21, No. 2, 202-217, United Kingdom: Taylor and Francis, 2013.

[20] Furlong, J, Maynard, T, Mentoring student teachers: The growth of professional knowledge, London and New York, Routledge, 1995.

[21] Goh, L.H, The Stages of Teacher Development and Teacher Professional Development: Focus on Teachers in Remote Areas, Academic Journal No. 10, 71-76, Gaya Teacher Training College, Kota Kinabalu, 2004.

[22] Johnston, Rita, Badley, Graham, The Competent Reflective Practitioner, Innovation \& Learning in Education, The International Journal for the Reflective Practitioner Vol. 2 Number 1 pp 4 - 10, MCB University Press, 1996.

[23] Goh, L.H, Considering the needs of beginning teachers, Academic Journal No. 12, 176-183, Gaya Teacher Training College, Kota Kinabalu, 2006.

[24] Goh, Lay Huah, ‘4r 2s’ Approach To Research: A Personal Philosophy For Change And Teacher Professional Development, Asian Education Action Research Journal (AEARJ), Vol. 1, 2012, ISSN 2289-3180.

[25] Schon, Donald A, The reflective practitioner: how professionals think in action, New York, Basic Books, 1983.

[26] Zeichner, K M, A critical analysis of reflection as a goal for teacher education, Educ. Soc. vol.29 no.103 Campinas May/Aug. 2008, http://dx.doi.org/10.1590/S0101-73302008 000200012, ISSN 1678-4626

[27] Goh, L.H, Considering the needs of beginning teachers, Academic Journal No. 12, 176-183, Gaya Teacher Training College, Kota Kinabalu, 2006.

[28] Goh, L.H, Considering the needs of beginning teachers, Academic Journal No. 12, 176-183, Gaya Teacher Training College, Kota Kinabalu, 2006.

[29] Goh, L.H, Loh, K.C, Let Them Fish, Educational Action Research Journal, Vol. 21, No. 2, 202-217, United Kingdom, Taylor and Francis, 2013.

[30] McDonald, Morva, Zeichner, Kenneth M, Social Justice Teacher Education, Editors: W. Ayers, T. Quinn, D. Stovall, Handbook of Social Justice in Education Publisher: Erlbaum, 2009.

[31] Davies, W.H, Songs of joy and others, London, A. C. Fifield, 1911.

[32] Goh, L.H, Collaborating with Adult Learners: Exploring the Role of a Facilitator, Academic Journal No. 7, 18-38, Gaya Teacher Training College, Kota Kinabalu, 2000.

[33] Goh, L.H, The Teacher as Researcher: Some Personal Viewpoints, Academic Journal No. 6, Gaya Teacher Training College, Kota Kinabalu, 1998.

[34] Goh, L.H, Collaborating with Adult Learners: Exploring the Role of a Facilitator, Academic Journal No. 7, Gaya Teacher Training College, Kota Kinabalu, 2000.

[35] Goh, L.H, Confronting Mediocrity in Teaching, Academic Journal, Gaya Teacher Training College, 2000.

[36] Goh, L.H, Approaching the Fourth Quadrant. Learning to Integrate ICT with Intel Teach, Research Presentation at the 
17th MELTA International Conference 2008, Palace of the Golden Horses, Kuala Lumpur, 30 Mei 2008

[37] Goh, L.H, The Conditions for Teacher Research in schools, Research Presentation at the Second Malaysia-Thai Joint Educational Research Conference 2009, Pullman Hotel, Bangkok, Thailand, 14 Nov 2009.

[38] Goh, L.H, Izyan Syazwani binti Zainuddin, Developing Language Fluency through Dialogue Journal Aong Lower Secondary Students. Academic Journal, Vol. 2, Institut Pendidikan Guru Kampus Gaya, Kota Kinabalu, 2009.

[39] Goh, L.H, Message Me Please: An Action Research on Using Message Cards to encourage writing, Research Presentation at the Asia Pacific Educational Research Association Conference at Putra World Trade Center, Kuala Lumpur, 22 - 26 November 2010.

[40] Goh, L.H, Jarrett, B.W, Mobile Phones and QR Codes: Fun with Listening and Speaking, Creative Teacher Showcase \& Workshop Presentation, MELTA Conference, Sunway Putra Hotel Kuala Lumpur, 28-29 May 2012.

[41] Goh, Lay Huah, '4r 2s’ Approach To Research: A Personal Philosophy For Change And Teacher Professional Development, Asian Education Action Research Journal (AEARJ), Vol. 1, 2012, ISSN 2289-3180.

[42] Goh Lay Huah, The Conditions For Teacher Research In Schools, Paper Presentation 2009, Second Malaysia-Thailand Joint Educational Research Conference 2009, Hotel Pullman Bangkok, Thailand, $14-18$ November 2009.

[43] Loughran, J., Mitchell, I., \& Mitchell, J, Learning from teacher research, Crows Nest, NSW, Allen \& Unwin, 2002.

[44] Borg, Simon (2006.) Conditions for Teacher Research. English Teaching FORUM - 2006 - Volume 44, Number 4 :Bureau of Educational and Cultural Affairs Office Of English Language Programs downloaded 29 September 2008 from http://forum.state.gov/vols/vol44/no4/p22.htm

[45] Burton, T, Exploring the Impact of Teacher Collaboration on Teacher Learning and Development, Doctoral dissertation, 2015, fromhttps://scholarcommons.sc.edu/etd/ 3107

[46] Richards, Keith, Qualitative Inquiry in TESOL, New York, Palgrave Macmillan, 2003.

[47] Goh Lay Huah, The Conditions For Teacher Research In Schools, Paper Presentation 2009, Second Malaysia-Thaila nd Joint Educational Research Conference 2009, Hotel Pullman Bangkok, Thailand, 14 - 18 November 2009.

[48] Eldridge, D; Stein, M, Wasko, A; and Peña, A, Coping With the Stumbling Blocks in Teacher Research in Teachers Taking Action: A Comprehensive Guide to Teacher Research, edited by Cynthia A. Lassonde and Susan E. Israel, International Reading Association, 2008, http://www.reading.org/Publish.aspx?page=bk463-8-Eldrid ge.pdf $\&$ mode $=$ retrieve $\& \mathrm{D}=10$.

1598/9780872074637.8\&F=bk463-8-Eldridge.pdf\&key $=8 B$ 636F4E-3A6A-4FE1-AB39-B743D80984E4

[49] Richards, Keith, Qualitative Inquiry in TESOL, New York, Palgrave Macmillan, 2003

[50] Sharp, C, Why should teachers be interested in research?,
SPARK - Secondary Practitioners Action Research Knowsley, 1, 2, 5-8, 2005, http://www.nfer.ac.uk/publicatio ns/other-publications/journal-articles/why-should-teachersbe-interested-in-research.cfm

[51] Nair, Sue, Teachers As Researchers: Researchers As Teachers? Towards Successful Educational Research, Malaysian Journal of Educators and Education, 22 . pp. 25-44, 2007.

[52] Goh Lay Huah, The Conditions For Teacher Research In Schools, Paper Presentation 2009, Second Malaysia-Thailand Joint Educational Research Conference 2009, Hotel Pullman Bangkok, Thailand, $14-18$ November 2009.

[53] Goh Lay Huah, The Conditions For Teacher Research In Schools, Paper Presentation 2009, Second Malaysia-Thailand Joint Educational Research Conference 2009, Hotel Pullman Bangkok, Thailand, $14-18$ November 2009.

[54] Goh Lay Huah, The Conditions For Teacher Research In Schools, Paper Presentation 2009, Second Malaysia-Thailand Joint Educational Research Conference 2009, Hotel Pullman Bangkok, Thailand, $14-18$ November 2009.

[55] Calderhead, James, Gates, Peter, Conceptualising Reflection In Teacher Development, UK, Taylor \& Francis, 2004.

[56] Nair, Sue, Teachers As Researchers: Researchers As Teachers? Towards Successful Educational Research, Malaysian Journal of Educators and Education, 22 . pp. 25-44, 2007

[57] Nair, Sue, Teachers As Researchers: Researchers As Teachers? Towards Successful Educational Research, Malaysian Journal of Educators and Education, 22 . pp. 25-44, 2007.

[58] Kitchen, Margaret, Jeurissen, Maree, Teacher Research As Tesol Professional Development: A Case Study New Zealand Journal Of Teachers' Work, Volume 3, Issue 1, 33-41, University of Auckland, 2006,http://www.teachersw ork.ac.nz/journal/volume3_issue1/kitchen.pdf

[59] Cochran-Smith, M., and S.L. Lytle. (2009). Inquiry as Stance: Practitioner Research for the Next Generation. New York: Teacher's College Press

[60] Nair, Sue, Teachers As Researchers: Researchers As Teachers? Towards Successful Educational Research, Malaysian Journal of Educators and Education, 22 . pp. 25-44, 2007.

[61] Stenhouse, L, The study of samples and the study of cases, British Educational Research Journal, 6, 1, 1-6, 1980.

[62] Sharp, C, Why should teachers be interested in research?' SPARK - Secondary Practitioners Action Research Knowsley, 1, 2, 5-8, 2005, http://www.nfer.ac.uk/publicatio ns/other-publications/journal-articles/why-should-teachersbe-interested-in-research.cfm

[63] Zeichner, K M, A critical analysis of reflection as a goal for teacher education, Educ. Soc. vol.29 no.103 Campinas May/Aug. 2008,http://dx.doi.org/10.1590/S0101-73302008 000200012, ISSN 1678-4626 
[64] Maslow, A.H, A Theory of Human Motivation, Psychological Review 50(4) (1943):370-96, An internet resource developed by Christopher D. Green, York University, Toronto, Ontario, 1943, ISSN 1492-3713, http://psychclassics.yorku.ca/Maslow/motivation.htm

[65] Stenhouse, L, The study of samples and the study of cases, British Educational Research Journal, 6, 1, 1-6, 1980.

[66] Zeichner, K M, A critical analysis of reflection as a goal for teacher education, Educ. Soc. vol.29 no.103 Campinas May/Aug. 2008, http://dx.doi.org/10.1590/S0101-73302008 000200012, ISSN 1678-4626

[67] Nair, Sue, Teachers As Researchers: Researchers As Teachers? Towards Successful Educational Research, Malaysian Journal of Educators and Education, 22 . pp. 25-44, 2007.

[68] Kitchen, Margaret, Jeurissen, Maree, Teacher Research As Tesol Professional Development: A Case Study New Zealand Journal Of Teachers' Work, Volume 3, Issue 1, 33-41, University of Auckland, 2006, http://www.teachersw ork.ac.nz/journal/volume3_issue1/kitchen.pdf

[69] Sharp, C, Why should teachers be interested in research?'
SPARK - Secondary Practitioners Action Research Knowsley, 1, 2, 5-8, 2005, http://www.nfer.ac.uk/publicatio ns/other-publications/journal-articles/why-should-teachersbe-interested-in-research.cfm

[70] Kitchen, Margaret, Jeurissen, Maree, Teacher Research As Tesol Professional Development: A Case Study New Zealand Journal Of Teachers' Work, Volume 3, Issue 1, 33-41, University of Auckland, 2006, http://www.teachersw ork.ac.nz/journal/volume3 issue1/kitchen.pdf

[71] Nair, Sue, Teachers As Researchers: Researchers As Teachers? Towards Successful Educational Research, Malaysian Journal of Educators and Education, 22. pp. 25-44, 2007.

[72] Goh, Lay Huah, ‘4r 2s’ Approach To Research: A Personal Philosophy For Change And Teacher Professional Development. Asian Education Action Research Journal (AEARJ), Vol. 1, 2012, ISSN 2289-3180.

[73] Bajunid, Ibrahim Ahmad, Not the Scions of Lesser Heritage and Ancestry, Keynote Address, 5th Asian/ASEAN Seminar on Educational Management and Leadership, 17 19 August 2007 at Legend Hotel Kuala Lumpur, 2007. 